\title{
Market Structure and Resource Depletion: A Contribution to the Theory of Intertemporal Monopolistic Competition*
}

\author{
JoSEPH E. STIGLITZ
}

Department of Economics, Princeton University, Dickinson Hall, Princeton, New Jersey 08540

AND

\section{Partha Dasgupta}

London School of Economics, University of London, Houghton Street, London, WC2A $2 A E$ England

Received December 4, 1978; revised January 16, 1980

\section{INTRODUCTION}

This paper is concerned with the effect of market structure on the rate of extraction of a natural resource ${ }^{1}$ and on the date of innovation of a substitute. It can be thought of as making a contribution to three separate bodies of literature:

(a) The Theory of Resource Extraction. In the model we present there exists a produced substitute ${ }^{2}$ to the natural resource. The primary question with which we are concerned is the interaction of the resource and its substitute. The model we present can thus be thought as providing a link between rent and production-based price theories.

One of the general results in the earlier literature on resource extraction is that deposits with lower extraction costs will be exploited first. The analysis

\footnotetext{
* This paper was completed while Stiglitz was Oskar Morgenstern Distinguished Research Fellow at Mathematica and visiting professor at the Institute for Advanced Study. We are most grateful to Richard Gilbert for useful discussions. Financial support from the National Science Foundation is gratefully acknowledged. This is a revised version of parts of Dasgupta and Stiglitz [6].

${ }^{1}$ The classic discussion of the theory of resource extraction is Hotelling. See also the Review of Economic Studies Symposium [4] and Dasgupta and Heal [5].

${ }^{2}$ This substitute is sometimes referred to as a "backstop" technology. Earlier discussions of the effect of the presence of the backstop technology on resource extraction can be found in Stiglitz [22] and Dasgupta and Heal [4].
} 
of this paper extends that result; in both competition and monopoly situations, all the resource is extracted before production of this new commodity is initiated. This seems to leave unexplained the observation that in many cases, substitutes have been produced prior to exhaustion of the resource. The model of limited competition presented in Section 7 does, however, provide an explanation of this phenomenon. ${ }^{3}$ Thus, although both polar forms of market organization, competition and monopoly, are productively efficient, mixed modes (limited competition) may not be.

(b) The Theory of Innovation. The "substitute" can be thought of as a new commodity (or an old commodity, the cost of production of which has just been dramatically reduced). It is widely recognized that the existence of a supply of a natural resource which is a substitute for the new commodity will lead to a delay in the introduction of the new commodity. (Indeed, this delay, which reduces the present discounted value of returns to doing research, has been the subject of some concern, that it provides a discouragement to undertaking research for the development of substitutes.) The second question with which this paper is concerned is characterizing this delay, both in competitive and non-competitive situations.

Although our concern with natural resources imposes a very specific structure on the problem, the analysis can be shown to be of much greater generality; if, instead of the "stock of natural resource" one thinks of "the stock of (old) machines employing the old technology," the problem of "how fast should the old machines be depreciated before the new technology is introduced" is formally equivalent to the problem analyzed here. ${ }^{4}$

(c) The Theory of Market Structure. The questions of the effect of monopoly both on the rate of extraction and on the timing of innovation have been subject to considerable discussion in the literature.

In the literature, one can find arguments that competition provides an inducement to innovation or, on the contrary, that at least some degree of monopoly is conducive to innovation (e.g., Schumpeter). Similarly, there is a widespread view that monopolies of natural resources may be excessively profligate (i.e., use resources too rapidly), and there is the contrary view that they are charging excessively high prices, and are thus being excessively conservationist. The arguments are complex and we cannot do justice in this

\footnotetext{
${ }^{3}$ Alternative explanations, based on technological characteristics, on capacity constraints, on demand characteristics (the different commodities are not perfect substitutes), or on imperfect capital markets ( a country with high-cost oil may not be able to borrow on the basis of future revenues), are clearly possible.

${ }^{4}$ There are some important differences prior to invention, and some technical differences between modeling the depreciation of a pre-existing stock of capital and the depletion of a pre. existing stock of natural resource.
} 
brief article to the various strands. ${ }^{5}$ The model we formulate does, however, provide precise answers to these questions.

In particular, we shall show that monopolies are excessively conservationist, ${ }^{6}$ in the sense that, at least initially, consumption of the natural resource is lower with monopoly than with competition, and that innovation occurs at a later data with monopoly than with competition.

There is another sense of "more conservationist," focusing on the date at which the resource is finally exhausted. (In the interpretation of the model which focuses on conventional goods produced by machines, the date of final exhaustion can be thought of as the date of final phasing out of the obsolete technology.) One of the other interesting results of our analysis is that this second sense may not coincide with the first; in one of the market structures examined, although the initial price is lower than the monopoly price, the date of exhaustion is later.

Finally, we turn to the question of examining the effect of limited (or monopolistic) competition ${ }^{7}$ on the allocation of resources. The analysis of markets in which firms have some limited degree of market power, less than pure monopoly but more than pure competition, has recently been the subject of a number of studies (Spence [20], Dixit and Stiglitz [11], Salop [18]). The market equilibrium which emerges in these models looks considerably different from either of the polar cases on which so much attention has been focused.

This suggests that further investigation of "mixed models" is likely to be fruitful. The models developed in this paper differ from most earlier models of imperfect competition in two significant ways. First, earlier literature on "imperfect" competition focused on models in which there were a few large firms (the theory of oligopoly), or in which there were a large number of small firms, each of whom had some limited market power (the theory of monopolistic competition). One of the distinguishing features of two of the models presented here is that there is one large firm and a large number of small extremely competitive firms. ${ }^{8}$ Secondly, most of the earlier models of imperfect competition were static. ${ }^{9}$ Yet the competitive process is essentially dynamic, e.g., new commodities replacing old, and this paper is an attempt

\footnotetext{
${ }^{3}$ For instance, the Schumpterian argument depends critically on the existence of fixed costs associated with innovation, on problems associated with appropriability, and with the existence of imperfect capital markets. All of these considerations will be ignored in this paper. But see Dasgupta and Stiglitz $[8,9]$ and Stiglitz et al., [28].

${ }^{6}$ The conditions under which these results obtain are given below.

"We prefer the term "limited" competition to the more prevalent term "imperfect" competition; as Stiglitz has argued [26], the traditional model of "perfect competition" does not really capture adequately the nature of competition in markets.

${ }^{8}$ See also Gilbert [12].

${ }^{9}$ Recent work on the theory of repeated games has shown how dramatically different results can be obtained with dynamic models.
} 
to capture some aspects of the essential intertemporal nature of the interactions in imperfectly competitive situations.

We are concerned here with two questions: First, is there a sense in which the properties of "limited competition" models can be thought of as lying between the "pure models" (pure competition, pure monopoly)? Our analysis casts some doubt on the traditional presumption, dating back at least to the work by Cournot [1], that limited competition lies between pure competition and pure monopoly: In one of the limited competition models examined, the initial price always lies between that which would have prevailed under competition and under pure monopoly. But in two models, the initial price exceeded both the competitive and the monopoly price. Moreover, in one model of limited competition that we examined (a duopoly model, in which the resource and the substitute are each owned by a single firm), the date of first innovation of the substitute preceded that of either the competitive equilibrium or the monopoly; the equilibrium for this model differed in a number of ways from both polar cases (sce below, Section 7).

Secondly, the presence of limited competition raises a number of new questions concerning interactions between the producer(s) of the two commodities, which simply do not arise in either of the polar cases. For instance, if the two producers co-exist, what determines market share? In Section 7, we provide an explicit solution for the determination of market share for the duopoly case.

Perhaps more importantly, a cartel can force a delay in innovation, in the entry by the competitive rivals with access to the new technology, by restricting the rate of extraction and therefore delaying the date of resource exhaustion. Whether it is in its interest to do so is a question we investigate in Section 6. (The answer is, under fairly general conditions, yes.)

Likewise, a monopolist owner of the substitute technology might lower his price (below his long run monopoly price), in order to "drive down" the price of resources, thus encouraging the exhaustion of the resource and hastening the date at which the patent holder can enjoy a monopoly position. In Section 5 we show that this is in fact the case, but that he only engages in this to a limited extent: as a consequence, the market equilibrium price turns out to be still higher than it would have been, had the substitute been competitively owned (thus the competitive owners of the resource benefit from the granting of a patent on the rival technology).

In what follows we shall study five distinct market structures: (I) where both the resource and the substitute technology are competitively owned; (II) where a single agent controls both; (III) where the resource is competitively owned but the substitute is protected by a patent; (IV) where the resource has been cartelized but the substitute is competitively exploited; and (V) where the resource is owned by a cartel and the substitute is protected by a patent owned by an agent other than the cartel, (the duopoly case). 
It may be useful, before beginning our analysis, to attempt to relate this study to several other recent studies of natural resources.

Stiglitz [25] established that if the elasticity of demand were constant and greater than unity and extraction costs were nil, then monopoly and competition were identical; if the elasticity of demand increased with output, and/or if extraction costs were positive, the monopoly was more conservationist than the competitive market. The results reported here can be thought of as extending these results to a more complicated set of technologies and market structures. ${ }^{10}$

In this paper, we do not ask what is the effect of the possibility of discovering a substitute on the rate of extraction prior to discovery. We begin our analysis with the discovery already made. The effect of the uncertainty about the date of discovery on the rate of extraction before invention is analyzed in Dasgupta and Stiglitz [10] for competitive markets and in Stiglitz and Dasgupta [27] for non-competitive market structures.

In this paper as well as the two papers referred to in the previous paragraph, we take the date of discovery as exogenous. But one of the primary reasons for examining the equilibrium in different market structures is that it affects the profitability of innovation, and hence the date of discovery.

Hence, this study can be thought of as a prelude to the sequel (Stiglitz et al. [28]), in which expenditures on $\mathrm{R} \& \mathrm{D}$, patterns of extraction, dates of invention and innovation and pricing policy are examined simultaneously under various market structures.

Finally, market structure itself should be viewed as endogenous, determined in part by the costs associated with innovation, the uncertainty associated with R \& D, and the legal structure. Dasgupta and Stiglitz $([8,9])$ developed a model in which market structure, invention, and innovation are all endogenous.

\section{The BASIC Model}

Let $x_{t} \geqslant 0$ and $y_{t} \geqslant 0$ denote respectively the rate of resource depletion and the flow of output from the substitute technology at date $t \geqslant 0)$. They are perfect substitutes in "consumption." ${ }^{11}$ Let $Q_{t}=x_{t}+y_{t}$, total consumption. For ease of exposition we take it that demand for the commodity does not

${ }^{10}$ For other studies of the effect of imperfect competition on resource depletion, see Salant [17], Sweeney [29], and Dasgupta and Heal [5, Chap. 11]. These contain analytical results. For simulation studies, see Cremer and Weitzman [2], and Hnyilicza and Pindyck [13].

${ }^{11}$ The commodity in question may be an input in production. In this case the demand for it is a derived demand. 
shift with time. Let $Q=D(p)(\geqslant 0)$ denote the market demand function. We take it that $D^{\prime}<0$. Let $f(Q)=D^{-1}(Q)=p$ be the inverse demand function. A central case in our analysis is that where the demand curve has constant elasticity,

$$
Q=k p^{-\epsilon}
$$

$\varepsilon$ is the (absolute value) of the elasticity of demand. As in any study of imperfect competition, we focus on the case where the elasticity exceeds unity, i.e., $\varepsilon>1$.

With the usual provisos assume that social benefits can be measured by consumer surplus (from the market demand function). Consequently, gross social utility is

$$
u(Q)=\int_{0}^{Q} f\left(Q^{\prime}\right) d Q^{\prime}
$$

For the constant elasticity demand function, we obtain

$$
u(Q)=\frac{k^{1 / \epsilon} \varepsilon}{\varepsilon-1} Q^{1-1 / \epsilon}
$$

There is no uncertainty. The intial stock is known to be $S_{0}$. Thus

$$
S_{t}=S_{0}-\int_{0}^{t} x_{\tau} d \tau \geqslant 0 \quad \text { for } \quad t \geqslant 0
$$

Moreover, extraction costs are nil. But the commodity can as well be made available by exploiting the substitute technology at a unit cost of production $\bar{p}(>0) .^{12}$

Our concern here is with monopolistic competition among the suppliers of the commodity in question. Therefore we take it that the capital market is perfect and that the market rate of interest on the numeraire asset is $r(>0)$. When the need arises (as it will in the following section), we shall identify $r$ as well with the social rate of discount. Without loss of generality, we take $k=((\varepsilon-1) / \varepsilon)^{\epsilon}$.

${ }^{12}$ The substitute "technology" could, of course, be simply a reserve of the natural resource with higher extraction costs $(\bar{p})$; the analysis here applies if the reserves are sufficiently large to drive rents close to zero. 


\section{The Competitive MARKeT}

This environment has been analyzed extensively, (see, e.g., Solow [19], Stiglitz [23] and [24] and Dasgupta and Heal [5]). We suppose that both the resource stock and the backstop technology are competitively owned. For our purposes here it will be best to obtain the characteristics of the intertemporal competitive equilibrium path by regarding the outcome as the solution of a planner's social optimization problem since we know, by the fundamental theorem of welfare economics, that the two are equivalent. The planner's problem is to choose two programs $x_{t}$ and $y_{t}$ so as to maximize

$$
\int_{0}^{\infty} e^{-r t}\left[Q^{1-1 / \epsilon}-\bar{p} y_{t}\right] d t
$$

subject to

$$
S_{t}=S_{0}-\int_{0}^{t} x_{\tau} d t ; \text { and } x_{t}, y_{t}, S_{t} \geqslant 0
$$

The solution of problem (3) is routine to establish. Let $p_{t}^{s}=f\left(Q_{t}\right)$ be the (shadow) price of the commodity. Then we know that as long as the resource stock lasts, price must rise at the rate of interest

$$
\dot{p}_{t}^{s} / p_{t}^{s}=r
$$

We can now describe the competitive equilibrium outcome in the form of

Proposrtion 1. The intertemporal competitive equilibrium consists of two phases. During an initial interval $\left(0, T^{*}\right), y_{t}=0$ and $x_{t}>0$ (i.e., the resource is exploited and the backstop technology is held in abeyance). During $\left(0, T^{s}\right)$ the resource price satisfies Eq. (4). At $T^{s}$ the resource is exhausted and innovation occurs. The initial price and the innovation date $\Gamma^{s}$ are related by the conditions

$$
p_{T^{s}}^{s}=p_{0}^{s} e^{r T^{s}}=\bar{p} \quad \text { and } \quad \int_{0}^{T^{s}} x_{t} d t
$$

For $t \geqslant T^{s}$ the backstop technology is in use, and the commodity is supplied at the price $\bar{p}$ (see Fig. 1).

The important result of Proposition 1 is that resource exhaustion precedes technological innovation. $T^{s}$ is the optimum date of innovation. Now this is not to say that resource exhaustion is the cause of innovation. Were the substitute technology not to be made available to society by $T^{s}$ the resource 


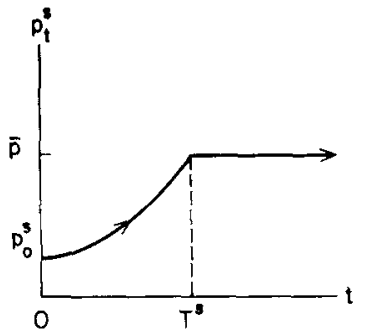

Figure 1

would not be exhausted at $T^{s}$ along a competitive equilibrium. It is precisely because the substitute technology is available that society finds it rational to exhaust the resource at $T^{s} .^{13}$

\section{Pure Monopoly}

This is the other polar case and is equally simple to characterize. It is supposed that a single firm both owns the resource stock and has a patent on the substitute technology. The motivation for analyzing this case is not solely hecause it is the direct generalization of the more conventional case of monopoly production, but also because the analysis is relevant for investigating the incentives that a resource cartel has for developing substitute products behind entry barriers.

Let $R(Q)=Q f(Q)$ denote gross revenue for the monopolist. Then the monopolists problem is to choose programs $x_{t}$ and $y_{t}$ so as to

$$
\left.\operatorname{maximize} \int_{0}^{\infty} e^{-r t} \mid R\left(x_{t}+y_{t}\right)-\bar{p} y_{t}\right] d t
$$

subject to

$$
S_{t}=S_{0}-\int_{0}^{t} x_{t} d t, \text { and } x_{t}, y_{t}, S_{t} \geqslant 0
$$

It is clear at once that the monopolist will not innovate prior to resource exhaustion. Moreover, as there are no extraction costs, the monopolist will so regulate his extraction that while stocks last, marginal revenue rises at the rate of interest,

$$
\dot{M}_{t} / M_{t}=r
$$

${ }^{13}$ This has an important bearing on the interpretation of certain historical episodes. For contrasting views of the "energy crisis" in 16th century England, see Nef [16] and Steinmuller [21]. The analytical issues are discussed in Dasgupta and Stiglitz [6]. 


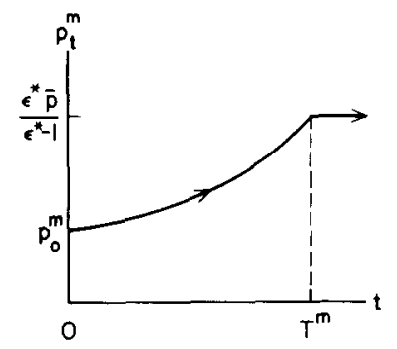

FIG. 2. $T^{m}$ is the date of innovation.

where

$$
M(Q)=R^{\prime}(Q) .
$$

The intuition behind (6) (which we shall find useful later) is that the monopolist must be indifferent between extracting a unit more at $t$, receiving an additional presented discounted value of revenue of $M\left(Q_{t}\right) e^{-r t}$, and selling a unit less at some later date, $\tilde{t}$, reducing the present discounted value of revenues then by $M\left(Q_{\tilde{t}}\right) e^{-r \tilde{t}}$, i.e.,

$$
M\left(Q_{t}\right) e^{-r t}
$$

must be the same for all $t$, from which (6) immediately follows.

The long run price (after all the resource is extracted) is that where marginal revenue equals marginal cost,

$$
M\left(Q_{\infty}\right) \equiv \bar{p}
$$

or

$$
p_{\infty}=\frac{\varepsilon^{*} \bar{p}}{\varepsilon^{*}-1},
$$

where

$$
\varepsilon^{*}=\frac{-f\left(Q_{\infty}\right)}{Q_{\infty} f^{\prime}\left(Q_{\infty}\right)}
$$

We can thus establish

Proposition 2a. The monopolist's optimal sales policy consists of two phases. During the first phase he holds the substitute technology in abeyance and controls the rate of extraction in such a way as to ensure that this marginal revenue grows at the rate of interest. He chooses the initial price in such a way that at the date market price equals the long-run monopoly price, the entire stock is exhausted. At this date the monopolist innovates and enters the second phase in which the product is sold at the long-run monopoly price, $\bar{p} \varepsilon^{*} /\left(\varepsilon^{*}-1\right)$. 
If the demand curves have constant elasticity, we know that marginal revenue is proportional to market price. Let $p_{t}^{(m)}$ denote the price charged by the monopolist. Then Eq. (6) reduces to

$$
\dot{p}_{t}^{m} / p_{t}^{m}=r
$$

Although $\left(6^{\prime}\right)$ and (4) are identical, this does not mean to say that the monopolist extracts at rates that are socially optimal. The two markets differ in "boundary conditions": on innovating, the monopolist will charge the monopoly price, $\bar{p} \varepsilon / \varepsilon-1>\bar{p}$, the long-run price of the social planner. Thus the monopolist's price exceeds the socially optimal price throughout, and the monopolist's rate of resource exploitation is more conservative at each date. This effect is reinforced if the elasticity of demand decreases with $Q$. It is now easy to establish

Proposition 2b. If

$$
\begin{gathered}
\varepsilon^{\prime}(Q) \leqslant 0, \quad p_{t}^{m}>p_{t}^{s}, \quad S_{t}^{m}>S_{t}^{s}, \\
\text { for all } t, \dot{p}^{m} / p^{m} \leqslant r \text { and } T^{m}>T^{s} .
\end{gathered}
$$

Similarly, if we let $p^{m}(S)$ be the equilibrium monopoly price when the stock of the resource is $S, p^{s}(S)$ be the competitive equilibrium price when the stock of the resource is $S$ and $T^{m}\left(S_{0}\right)$ and $T^{s}\left(S_{0}\right)$ be the innovation dates as a function of the initial stock, then we can establish ${ }^{14,15}$

${ }^{14}$ The proof is straightforward. From Eq. (6) we have

$$
\begin{aligned}
\frac{d \ln M}{d t} & =\frac{\dot{p}}{p}+\frac{\varepsilon^{\prime}}{\varepsilon^{2}} \frac{\dot{Q}}{Q} \frac{\varepsilon Q}{\varepsilon-1} \\
& =\frac{\dot{p}}{p}\left(1-\frac{\varepsilon^{\prime} Q}{(\varepsilon-1)}\right)=r .
\end{aligned}
$$

If

$$
\frac{\varepsilon^{\prime}}{\varepsilon-1}>0, \quad \frac{\dot{p}}{p}>r
$$

Thus

$$
\frac{d p^{m}}{d S}=\frac{d p / d t}{d S / d t}=-\frac{p r}{\left(1-\varepsilon^{\prime} Q / \varepsilon-1\right) Q}
$$

while

$$
\frac{d p^{s}}{d S}=-\frac{p r}{Q}
$$

${ }^{15}$ If speculators can buy the natural resource and store it, the monopolist is constrained to price-quantity trajectories for which $\dot{p} / p \leqslant r$. Then the case of $\varepsilon^{\prime}(Q)>0$ is identical to that with $\varepsilon$ constant. 


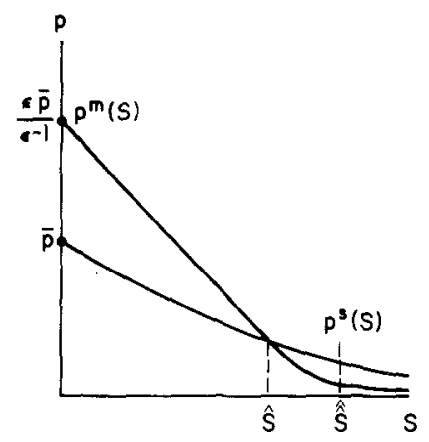

Fig. 3. $\varepsilon^{\prime}>0$ : For large $S$ monopoly is excessively profligate.

Proposition 2c. If $\varepsilon^{\prime}(Q)>0$, there exists critical values of the initial stock, $\hat{S}$ and $\hat{S}, 0<\hat{S}<\hat{S}$, such that

$$
\begin{aligned}
p^{m}\left(S_{0}\right) \gtrless p^{s}\left(S_{0}\right) \quad \text { as } & S_{0} \lesseqgtr \hat{S}, \\
T^{m}\left(S_{0} \gtrless T^{s}\left(S_{0}\right) \quad\right. \text { as } & S_{0} \lesseqgtr \hat{S}
\end{aligned}
$$

(see Fig. 3).

For the central case of constant elasticity, monopoly is not only excessively conservationist, but innovation is delayed (corroborating the view that monopoly discourages innovation; but see Stiglitz et al. [28]). This result extends to the case of $\varepsilon^{\prime}<0$, and, for small initial stocks of the resource, to $\varepsilon^{\prime}>0$; but just the opposite happens if $\varepsilon^{\prime}>0$ and $S$ is large.

The monopolist's fault lies not in the fact that he holds a sleeping patent during the first phase; for we concluded in Section 3 that the existence of a new technology is not an argument for introducing it. His fault lies rather in allowing the patent to sleep for too long. ${ }^{16}$

Although our primary concern in this paper is with the effect of market structure on the price of a natural resource and patterns of extraction, for a given stock of the natural resource and a given price of the substitute, we are also concerned with the incentives, under each of the market structures examined, for changes in the available stock of resources, as a result of additional explorations, or changes in the date of invention, as a result of increased expenditures on $R \& D$. In non-competitive environments, these incentives are related to, for instance, the marginal revenue obtained by a resource owner from an additional unit of the resource at any particular date. Thus, in our later analysis, the following result, which may be derived immediately from our earlier discussion, is of some use:

\footnotetext{
${ }^{16}$ It is easy enough to confirm that Proposition $2 b$ holds if we introduce a small positive unit cost of extraction.
} 
Proposition 2d. For all $S_{0}$, if $\varepsilon^{\prime}(Q) \leqslant 0$

$$
M_{t}^{m}<p_{t}^{s} \quad \text { all } t .
$$

If $\varepsilon^{\prime}(Q)>0$,

$$
M_{t}^{m} \lesseqgtr p_{t}^{s} \quad \text { all } t \text { as } S_{0} \lesseqgtr \hat{S} .
$$

The result follows from observing that at $T^{m}$.

$$
M^{m}-\bar{p},
$$

while at $T^{s}$

$$
p^{s}=\bar{p},
$$

and both increase exponentially at the rate $r$ until $T=T^{m}\left(T=T^{s}\right)$.

Assume that the expected cost of discovering a unit of the natural resource is $c_{t}$; assume, moreover, that $c_{t}$ increases with $t$, and, in particular, that it increases at a rate faster than $r .{ }^{17}$ Then, it is immediate that the amount of exploration with monopoly is less than is socially optimal if $\varepsilon^{\prime} \leqslant 0$.

\section{Competitive Resource Owners and Monopoly Producer}

Consider a resource that is competitively owned, and suppose that the substitute technology is protected by a patent. To keep the analysis tidy we take it that the patent is of infinite duration. Interest in this form of market structure lies in the fact that it sets the stage for an exploration of decentralized search for a substitute product under the provision that the winner takes all.

We now need to develop a dynamic game equilibrium for this market structure. The natural equilibrium concept is that of von Stackelberg. Since resource owners are competitive and since we shall hypothesize the existence of forward markets the percentage rate of change in the resource price can ncver exceed $r$. This is a constraint that the patent holder must observe in the process of price setting. (In the absence of futures markets, important problems of dynamic consistency arise.)

It is conceptually simplest to analyze the game equilibrium by supposing

${ }^{17}$ This way of modeling exploration costs does not do full justice to the technology of exploration; we should also make $c$, depend on, for instance, previous discoveries. What this formulation does capture, however, is the fact that exploration and extraction can occur at distinctly different times. (With exploration costs, the natural resource becomes like a "produced good"; there still, of course, may be rents associated with its production.) 
that the patent holder purchases the entire resource stock at the initial data and consequently determines the rate of extraction. But, as we have already noted, he can exercise only partial control.

Let $\tilde{p}_{t}$ denote the equilibrium price at $t$. Then the equilibrium path generated in this imperfectly competitive market is obtained from the solution of the following problem:

$$
\underset{\left(y_{t}, x_{t}, \tilde{p}_{0}\right)}{\operatorname{Maximize}} \int_{0}^{\infty} e^{-r t}\left[R\left(x_{t}+y_{t}\right)-\bar{p} y_{t}\right] d t-\tilde{p}_{0} S_{0}
$$

subject to

$$
S_{t}=S_{0}-\int_{0}^{t} x_{\tau} d \tau ; \frac{\dot{p_{t}}}{\tilde{p}_{t}} \leqslant r \text { and } x_{t}, y_{t}, S_{t} \geqslant 0
$$

Problem (7) is of an unusual form, though it can be solved rather readily. It differs from problem (5) (the case of the pure monopolist) in precisely two ways. First, there is an additional cost item (the purchase of the resource from the competitor owners) in the patent holder's profit function. Second, there is a constraint on the rate at which he can raise prices. Now we noted in Proposition $2 b$ that the resource price never rose at a rate greater than $r$ along the solution to problem (5) if $\varepsilon^{\prime} \leqslant 0$. One might have thought then that the constraint on the price in problem (7) is really irrelevant. Not so. For suppose that the patent holder could ignore this constraint. The solution to (7) would then be immediate. He would set $\tilde{p}_{0}=0$ and sell the entire stock at $t=0$. This would enable him to get down to producing the substitute product right from the start and to sell it at the monopoly price. It is such a discontinuous jump in the price that is prohibited by the constraint.

In Appendix A, we prove that,

Proposition 3a. The dynamic game equilibrium is characterized by the following properties: There exist $\tilde{T}_{1}$ and $\tilde{T}_{2}$, with $\tilde{T}_{2}>\widetilde{T}_{1}>0$, such that

(i) $\dot{p}_{t} / \tilde{p}_{t}=r$ for $0 \leqslant t<\tilde{T}_{2}$ and $\tilde{p}_{0}$ and $\tilde{T}_{2}$ are related by the condition $\tilde{p}_{0} e^{r \tilde{T}_{2}}=\varepsilon^{*} \bar{p} /\left(1-\varepsilon^{*}\right)$ (the long-run stationary price);

(ii) $\tilde{p}_{t}=\varepsilon^{*} \bar{p} /\left(1-\varepsilon^{*}\right)$ for $t \geqslant \tilde{T}_{2}$;

(iii) during an initial interval $\left(0, \tilde{T}_{1}\right)$ the backstop is held in abeyance and only the exhaustible resource is marketed and at $\tilde{T}_{1}$ the entire stock of the resource is depleted. Consequently,

(iv) during $\left(\tilde{T}_{1}, \tilde{T}_{2}\right)$ the patent holder produces the substitute product and earns positive but less than the full monopoly profit. (See Fig. 4a). The present discounted value of profits earned during $\left(0, \tilde{T}_{1}\right)$ equals $\tilde{p}_{0} S_{0}$. 

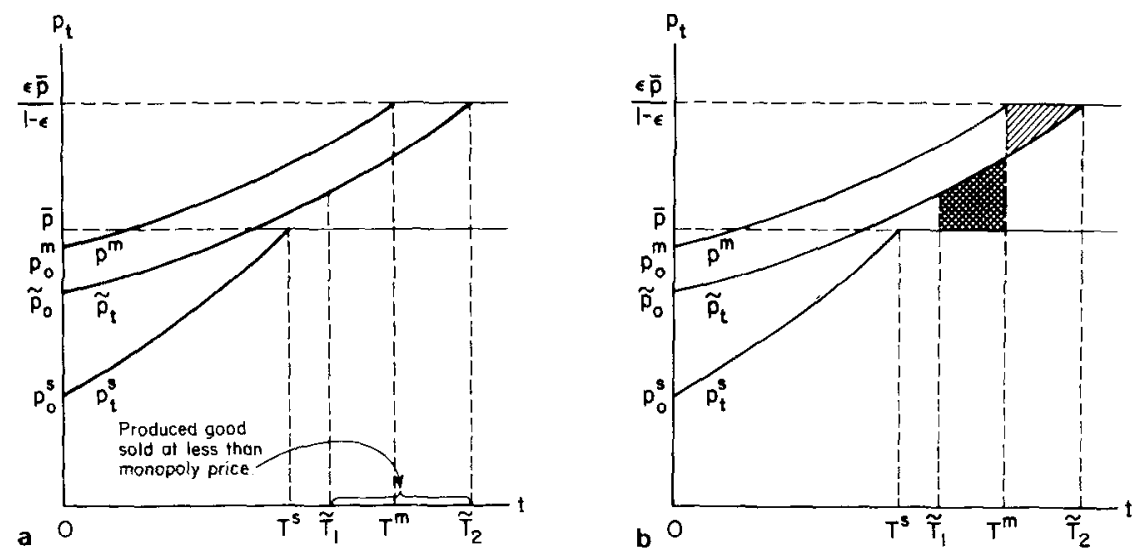

FIG. 4. $\quad \tilde{T}_{1}$ is the date of innovation. (a) Stackleberg equilibrium. (b) $\tilde{p}_{0}>p_{0}^{s}$.

Parts (i)-(iii) of Proposition $3 \mathrm{a}$ are obvious enough. The problem confronting the patent holder is one of devising the optimal procedure for driving his competitive rival out of business. Presumably he wants to announce a "low" sequence of prices for a time so as to encourage depletion, to hasten the day when he can be the sole producer of the commodity. He can do this best by allowing the market price to rise at the maximum rate consistent with dynamic equilibrium.

It is part (iv) of Proposition 3a which requires justification. The argument establishing part (iv) of Proposition 3a can be presented diagrammatically. In Fig. 4 a we bring together Fig. 1 and 2 on the supposition that each of the three systems initiates with the same stock $S_{0}$, and the assumption that $S_{0}$ is "large" so that initial price under pure monopoly (Fig. 2) is less than $\bar{p}$. If $\tilde{p}_{0}>p_{0}^{m}$ then $\tilde{T}_{1}$ (the date at which the resource gets depleted) exceeds $T^{m}$. Since over the entire interval $\left(0, \tilde{T}_{1}\right)$ the patent holder earns no net profit, in setting $\tilde{p}_{0}>p_{0}^{m}$ he would merely delay the date from which he can earn profits from the new technology. This argument by itself suggests that he would like to set $\tilde{p}_{0}$ at a lower level. For, lowering the initial price brings nearer $\tilde{T}_{1}$, the date at which he begins marketing his product. But bringing forward $\tilde{T}_{1}$ also implies that for an interval of time the price at which he can sell his product is lowered. Thus, in comparing any two price paths we must compare the revenues corresponding to the shaded areas in Fig. 4b. The cross-hatched area in the figure shows the increased profits in the interval $\left(\tilde{T}_{1}, T^{m}\right)$ from having lowered the initial price from $p_{0}^{m}$, and the striped area denotes the subsequent reduced profits.

Note that as $\widetilde{T}_{1} \rightarrow T^{m}, \widetilde{T}_{2} \rightarrow T^{m}$, and both areas go to zero. Thus, to establish $\tilde{T}_{1}<\tilde{T}_{2}$ requires a more subtle argument (see Appendix A).

The next question is, will the patent holder set $\tilde{p}_{0}<p_{0}^{s}$ ? The answer is, 
"no." For were he to set $\tilde{p}_{0}<p_{0}^{s}$ (so that $\tilde{T}_{1}<T^{\S}$ ) there is now an additional interval during which he absorbs a loss before $\tilde{p}$ reaches $\bar{p}$ and during the remaining period his profits are lower. These two arguments establish his optimal initial price, $\tilde{p}_{0}$, at a level strictly between $p_{0}^{s}$ and $p_{0}^{m}$.

The fact that $\tilde{p}_{0}>p_{0}^{s}$ implies that the market value of the resource is higher if the substitute technology is awarded a patent than it would be were it competitively owned. Therefore, so far as the competitive resource owners are concerned, monopolization of the new technology is an advantage. Some of the benefits of the monopoly "trickles" down to the competitive resource owners.

In establishing Proposition 3a we have also established ${ }^{18}$

Proposition 3b. (i) If elasticity of demand is constant,

$$
\begin{gathered}
p_{t}^{s}<\tilde{p}_{t}<p_{t}^{m} \quad \text { for all } t, \\
T^{s}<\tilde{T}_{1}<T^{m}<\tilde{T}_{2} .
\end{gathered}
$$

(ii) If $\varepsilon^{\prime}(Q)<0$,

$$
p_{t}^{s}<\tilde{p}_{t} \quad \text { and } \quad T^{s}<\tilde{T}_{1} \text {. }
$$

$\tilde{p}(S)<p^{m}(S)$

(iii) If $\varepsilon^{\prime}(Q)>0$

$$
p_{t}^{s}<\tilde{p}_{t} \quad \text { and } \quad T^{s}<\tilde{T}_{1}, T^{m}<\tilde{T}_{2} .
$$

If the resource is competitively owned, but the substitute is controlled by a monopolist, then if demand has constant elasticity the date of innovation and the date of exhaustion of the natural resource (which coincide) is later than is socially optimal, but earlier than for a pure monopolist, and the initial price always lies between the socially optimal price and the pure monopoly price.

The case with non-constant elasticity demand curves is more complicated, and is discussed in Appendix A. The price is always greater than the socially optimal price; moreover, the date of innovation is later than is socially

${ }^{18}$ If $\varepsilon^{\prime}(Q)<0, \dot{p}^{m} / m^{m}<r$, so if $\tilde{p}_{0}>p_{0}^{m}, T^{m}<\tilde{T}_{1}$, but $p^{m}\left(T^{m}\right)<\tilde{p}\left(\tilde{T}_{1}\right)<<\bar{p} \varepsilon /(1-\varepsilon)$, contradicting Proposition 2a. 


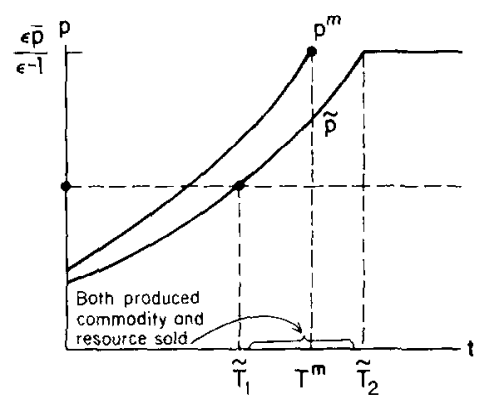

Fig. 5. Nash (quantity) equilibrium.

optimal. The comparison with the pure monopoly is complicated by the fact that in pure monopoly, price may rise faster or slower than the rate of interest.

The solution concept we have used here is the traditional Stackelberg leader (the monopolist)-follower (the competitive producers) model, which, at least in a temporal context, seems quite persuasive whenever there is a single dominant firm dealing with a large number of small rivals, who act as price-takers. An alternative, and we think in this context less persuasive solution concept, is the traditional Nash equilibrium quantity-taking equilibrium. Then we can establish

Proposition 3c. The Nash quantity-taking equilibrium is characterized by:

(i) An initial phase during which prices rise (approximately) at the rate of interest and during which only the resource is extracted,

$$
\frac{\dot{p}}{\tilde{p}}=r, \quad 0<t<\tilde{T}_{1}, \tilde{y}_{t}=0,
$$

and

$$
\tilde{p}_{t} \leqslant \bar{p}
$$

(ii) a second phase, $\tilde{T}_{1}<t<\tilde{T}_{2}$, during which prices lie between $\bar{p}$ and $\bar{p} \varepsilon^{*} /\left(\varepsilon^{*}-1\right)$ (the competitive and monopoly prices, respectively) and still rise at the rate of interest, but both the natural resource and the produced good are produced. The quantity produced satisfies the equation

$$
\text { marginal revenue }=p_{t}\left(1-\frac{\left(1-\mu_{t}\right)}{\varepsilon}\right)=\tilde{p}=\text { marginal cost }
$$

where $1-\mu_{t}=$ fraction of output supplied by monopolist; and 
(iii) a third phase, $t>\tilde{T}_{2}$ during which only the produced good is sold

$$
\left(\tilde{x}_{t}=0, \tilde{y}_{t}>0\right), \quad \text { and } \quad p_{t}=\bar{p} /\left(1-1 / \varepsilon^{*}\right) \text { (see Fig. 5). }
$$

The argument is straightforward: For each of the competitors, who supply a negligible fraction of the market, price is approximately equal to marginal revenue; hence, so long as they sell, price must rise at the rate of interest. On the other hand, the monopolist produces to the point where his perceived marginal revenue equals his marginal cost.

An immediate corollary of this result is:

Propositron 3d. In the Nash equilibrium:

(i)

$$
\begin{gathered}
p_{t}^{s}<\tilde{p}_{t} \quad \text { for all } t . \\
\tilde{T}_{1}<T^{s}<\tilde{T}_{2} ;
\end{gathered}
$$

the price always exceeds the socially optimal price; the date of innovation is earlier than in the social optimum; the date of exhaustion is later. ${ }^{19}$

(ii) If $\varepsilon^{\prime}=0, \tilde{p}_{t}<p_{t}^{m}$ for all $t<\tilde{T}_{2}$,

$$
\tilde{T}_{1}<T^{m}<\tilde{T}_{2} .
$$

If the elasticity of demand is constant, the price is always less than the monopoly price, and the date of innovation is earlier, but the date of exhaustion is later.

(iii) If $\varepsilon^{\prime}(Q)<0, \tilde{p}_{0}<p_{0}^{m}$ and $\tilde{T}_{1}<T^{m}$. If $\varepsilon^{\prime}(Q)>0, \tilde{T}_{2}>T^{m}$.

The implications of the results for exploratory activity are immediate. Since the price is higher than in the social optimum, exploratory activity will be greater: some of the potential monopoly profits of the inventor will be eroded by exploratory activity.

\section{Resource Cartel and Competitive Producers}

The problem analyzed in the previous section corresponds to the optimal procedure for a monopolist driving his competitive rivals out of the market. The case to be analyzed in this section is the opposite. Here the resource is

${ }^{19}$ Assume $p_{0}^{s} \geqslant \tilde{p}_{0}$. Then the date at which $p^{s}=\bar{p} . T^{s}>\tilde{T}_{1}$, the date at which $\tilde{p}_{t}=\bar{p}$. But $\tilde{S}_{\tilde{T}_{1}}>0$, while $S_{T^{s}}^{s}=0$. But since $x_{t}^{s}<\tilde{x}_{t}$, this is impossible. Hence $p_{0}^{s}<\tilde{p}_{0}$. It is thus immediate that $\tilde{T}_{1}<T^{s}$. Since $\tilde{p}_{t}>p_{t}^{s}$, and $\mu_{t}>0$ for all $\tilde{T}_{1}<t<\tilde{T}_{2}, x_{t}^{s}>x_{t}$ for all $t \leqslant \tilde{T}_{2}$. Hence $\tilde{T}_{2}>T^{s}$ (the data of exhaustion must be later). 
managed by a cartel. The new technology is the competitive sector. The cartel obviously cannot keep these competitive rivals out of the market indefinitely. It can merely undercut them for a while. For, so long as the cartel produces at a sufficient rate so as to keep the market price below $\bar{p}$, competitive producers do not produce. They would suffer losses were they to do so. Nor can it ever hope to sell at a price in excess of $\bar{p}$, for in this case the competitive rivals would undercut it. (This form of imperfect competition has been analyzed independently by Hoel [14].)

Let $p_{t}^{*}$ be the price along the game equilibrium. Then the equilibrium outcome is the solution of the following problem:

$$
\underset{\left(x_{t}, y_{t}\right)}{\operatorname{Maximize}} \int_{0}^{\infty} e^{-r t}\left[R\left(x_{t}+y_{t}\right)-\bar{p} y_{t}\right] d t
$$

subject to

$$
S_{t}=S_{0}-\int_{0}^{t} x_{\tau} d \tau ; x_{t}, y_{t} S_{t} \geqslant 0 ; \text { and } p_{t}^{*} \leqslant p
$$

It will be noted that (8) differs from (5) only by the inclusion of the final constraint on the market price. The threat of entry by the competitive sector ensures that price never exceeds $\bar{p}$.

In Appendix B we prove that the equilibrium outcome can now be stated as:

Proposition 4a. There exist two instants $T_{1}^{*}$ and $T_{2}^{*}$ (with $\left.T_{2}^{*}>T_{1}^{*} \geqslant 0\right)$ such that the cartel is the sole supplier to the market during $\left(0, T_{2}^{*}\right)$. During $\left(0, T_{1}^{*}\right)$ the cartel so controls supply that marginal revenue rises at the rate of interest, and that at $T_{1}^{*}$ price is $\bar{p}$. During $\left(T_{1}^{*}, T_{2}^{*}\right)$, the cartel markets the remaining stock at the price $\bar{p}$. At $T_{2}^{*}$ the stock is exhausted and the competitively owned backstop technology makes its

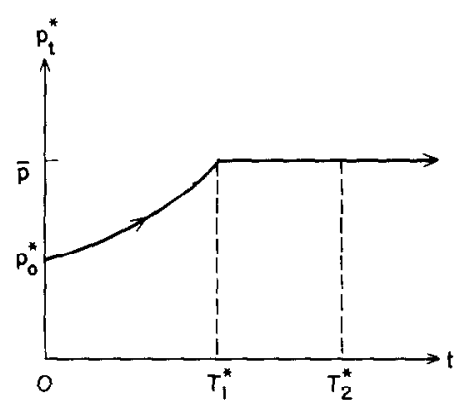

FIG. 6. $T_{2}^{*}$ is the date of resource exhaustion and technological innovation. 

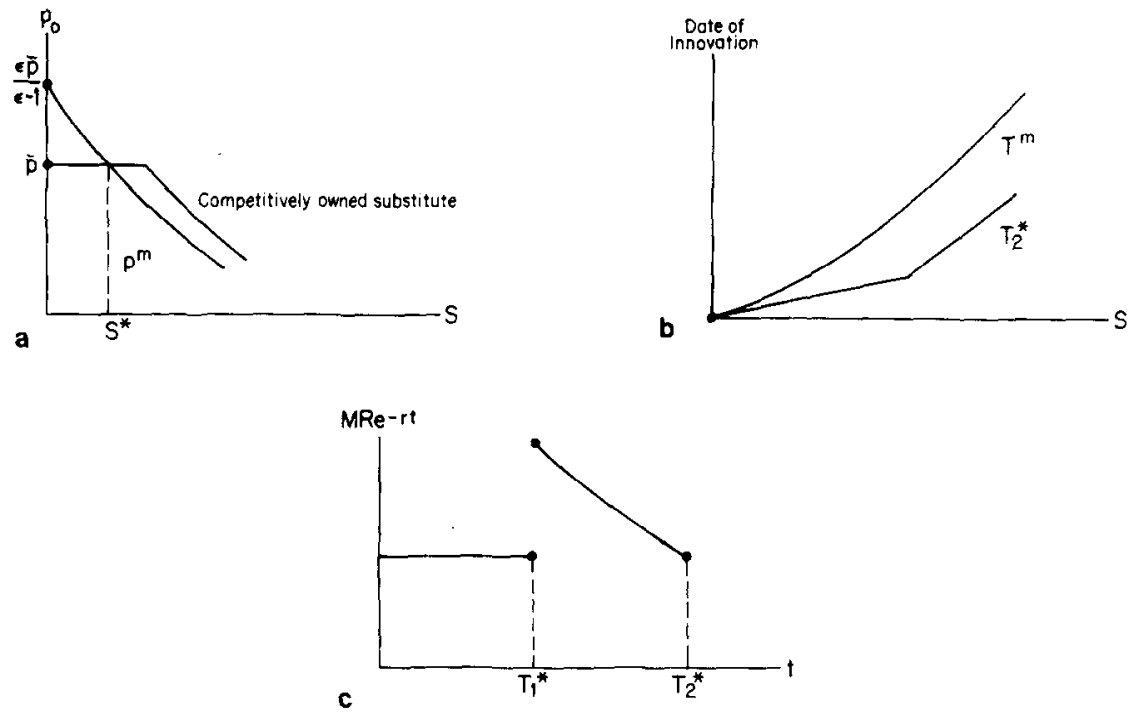

FIG. 7. (a) For large $S$, competition increases price. (b) Competitive ownership of substitute leads to earlier innovation. (c) Discontinuity in marginal revenue.

appearance and for $t \geqslant T_{2}^{*}$ the product is to be sold at $\bar{p} . T_{1}^{*} \geqslant 0$ as $S_{0} \geqslant$ $-\left(f^{-1}(\bar{p}) / r\right) \ln (1-1 / \varepsilon)$. At $T_{1}^{*}$, there is a discontinuous jump in marginal revenue; its present value at $T_{2}^{*}$ is the same as during the interval $\left(0, T_{1}^{*}\right)$. (See Fig. 6 and 7.)

The key feature of Proposition 4a (if one were to contrast it with Proposition 2) is the limit pricing phenomenon that prevails during $\left(T_{1}^{*}, T_{2}^{*}\right)$. It does not occur immediately in the economy here because we have postulated an elastic demand curve. If instead, demand were inelastic at prices less than $\bar{p}$ it is clear that the limit price phenomenon would occur from the start (i.e., $T_{1}^{*}$ would be zero).

The fact that $T_{2}^{*}>T_{1}^{*}$ implies that the resource is depleted at a more conservative pace than in a fully competitive economy (Proposition 1), and innovation occurs at a later date (see Fig. 1 and 6).

It can also be established that if $S$ is large enough (so $p_{0}^{m}<\bar{p}$ ), the initial price is greater than the initial monopoly price. To see this, observe that for all dates in the interval $\left(0, T_{1}^{*}\right)$, the present discounted value of the marginal revenue is constant. In addition, optimality requires that this be equal to the present discounted value of selling a unit more at $T_{2}^{*}$, i.e., $\bar{p} e^{-r T_{2}^{*}}$. Assume $p_{0}^{*}=p_{0}^{m}$. Then, at the date of exhaustion, the present discounted value of marginal revenue for the monopoly is

$$
\bar{p} e^{-r T^{m}} \text {. }
$$


But $T^{m}$ would clearly exceed $T_{2}^{*}$, and hence the value of the marginal revenue at time 0 ,

$$
p_{0}^{*}(1-1 / \varepsilon)
$$

must be less than $\bar{p} e^{-r T_{2}^{*}}$. Hence, it pays the firm to reduce extraction at time 0 (increase marginal revenue at time 0 ), which will increase $T_{2}^{*}$, and hence lower the marginal revenue at the date of exhaustion.

A similar argument can be used to show $T_{2}^{*}<T^{m}$. For assume $T_{2}^{*}=T^{m}$. Then the present discounted value of marginal revenue, in both market structures, is $\bar{p} e^{-r T_{2}^{*}}=\bar{p} e^{-r T_{m}}$. But when the substitute is competitively produced, $p_{0}^{*}>p_{0}^{m}$, and hence at $t=0$, marginal revenue exceeds that in the pure monopoly; hence marginal revenue at $t=0$ exceeds that at $T_{2}^{*}$. The result is immediate (See Fig. $7 \mathrm{~b}$.)

It is obvious that for small $S$, where $p_{0}^{m}>\bar{p}, p_{0}^{*} \leqslant \bar{p}<p_{0}^{m}$. The relationship between the two, plotted as a function of $S$, is given in Fig. 7a.

We summarize with

Proposition $4 b^{20}$

$$
\begin{array}{ll}
p_{0}^{*} p_{0}^{s} \quad \text { if } \varepsilon^{\prime} \leqslant 0, & \\
p_{t}^{*} \geqslant p_{t}^{s} & \text { all t if } \varepsilon^{\prime}=0, \\
T_{2}^{*} \geqslant T^{s} & \text { if } \varepsilon^{\prime} \leqslant 0, \\
p_{t}^{*} \gtrless p_{t}^{m} & \text { as } S \gtrless S^{*}, \\
T_{2}^{*}<T^{m}, & \\
M_{0}^{*}>M_{0}^{m} . &
\end{array}
$$

Note that in this model, the limited competition equilibrium price may be greater than both the monopoly price and the competitive equilibrium price. Competition increases marginal revenue.

\section{INTERTEMPORAL DUOPOLY EQUILIBRIUM}

A telling feature characterizing the equilibrium outcome of each of the four market structures ${ }^{21}$ that we have so far analyzed is that resource exhaustion precedes technological innovation. In each the cheaper resource is

\footnotetext{
${ }^{20}$ The proof of (a) is analogous to our proofs of earlier propositions. If $\varepsilon^{\prime}<0$ price rises slower than the rate of interest. Hence, if $p_{0}^{*} \leqslant p_{0}^{s}$, the date of exhaustion must be earlier; in particular it must occur before $p_{t}^{*}=\bar{p}$, contradicting Proposition $4 \mathrm{a}$.

${ }^{21}$ With the exception of the Nash equilibrium solution to the model of Section 5.
} 
supplied first. Transition from the exhaustible to the inexhaustible resource occurs sharply. Neither of these intuitively appealing characteristics are a feature of a duopoly equilibrium.

Assume then that the resource has been cartelized and that the new technology is protected by a patent held by a rival. To simplify the analysis we take it that the patent is of infinite duration. The aim is to characterize an intertemporal Cournot-Nash equilibrium, i.e., we assume that each of the duopolists takes the quantities marketed by the other as given. A game equilibrium then requires that so long as the two supply the market simultaneously the perceived net marginal revenue to the resource cartel rises at the rate of interest and the perceived marginal revenue accruing to the patent holder equals $\bar{p}$. This is the general property under which the rivals share the market.

Thus, let $\mu_{t}$ be the fraction of total output, $Q_{t}$, sold by the natural resource owner at $t$. For the resource owner, marginal revenue is given by

$$
p_{t}+\mu_{t} Q_{t} \frac{d p}{d Q}=p_{t}\left(1-\mu_{t} / \varepsilon\right)
$$

while for the patent owner, it is

$$
p_{t}\left(1-\left(1-\mu_{t}\right) / \varepsilon\right)
$$

If $0<\mu_{t}<1$, the marginal revenue of the resource owner must be rising at the rate of interest, i.e.,

$$
\frac{\dot{p}}{p}-(\dot{\mu} / \varepsilon-(\mu / \varepsilon) \dot{\varepsilon} / \varepsilon) \frac{1}{1-\mu / \varepsilon}=r
$$

and the marginal revenue of the patent owner must be equal to his marginal cost,

$$
p(1-(1-\mu) / \varepsilon)=\bar{p}
$$

Manipulating (10a) and (10b) yields

$$
\frac{\dot{p}}{p}=r \frac{2-1 / \varepsilon-\bar{p} / p}{2-1 / \varepsilon-v} \equiv r \psi
$$

where $v=Q \varepsilon^{\prime} / \varepsilon$. (See Appendix C.) We assume $v<2-1 / \varepsilon$. Thus, provided $v \leqslant 0, \dot{p} / p<r$, price rises slower than in competitive equilibrium; from the corresponding equation for the pure monopolist, we can show that 

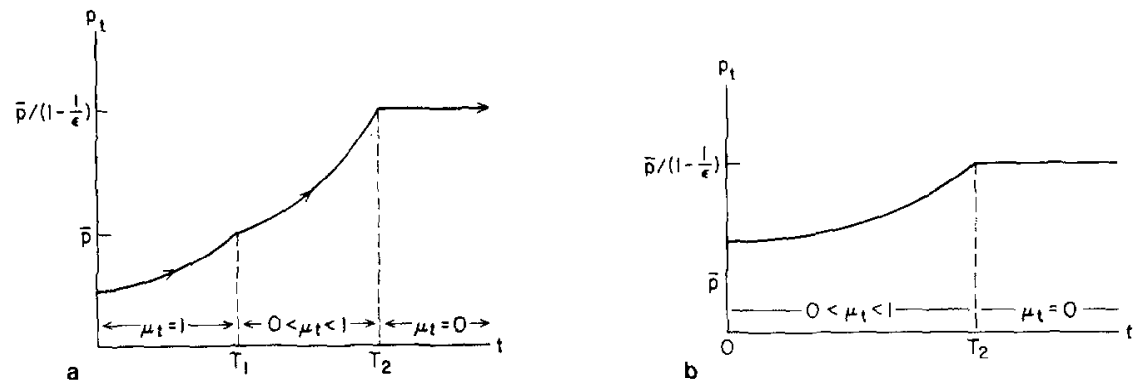

FIG. 8. (a) $S_{0}$ is large. $T_{1}$ is the date of innovation. Duopolists share the market during $\left(T_{1}, T_{2}\right) . T_{2}$ is the date of resource exhaustion. $\left.T_{2}-T_{1}=-(2 / r) \log (1-1 / \varepsilon)\right)$. (b) $S_{0}$ is small. Innovation occurs at $t=0 . T_{2}$ is the date of resource exhaustion.

price rises more slowly than for a monopolist, ${ }^{22}$ provided $v$ is positive (or not too negative).

We can use these results to prove

Proposition 5a. If $S_{0}$ is large, the duopoly equilibrium is characterized by three phases:

(a) During the first phase $\left(0, T_{1}\right), p_{t}<\bar{p}$, the cartel is the sole supplier, and marginal revenue rises at the rate of interest.

(b) During the second phase $\left(T_{1}, T_{2}\right), \bar{p} \leqslant p_{t} \leqslant \bar{p} \varepsilon^{*} /\left(1-\varepsilon^{*}\right)$, price is above the competitive price but below the pure monopoly price; the duopolists share the market, and the rate of change of price is given by (11). Exhaustion of the resource occurs at $T_{2}$.

(c) During the third phase, $t>T_{2}, p=\bar{p} \varepsilon^{*} /\left(1-\varepsilon^{*}\right)$, only the substitute is produced; it is sold at the long-run monopoly price. See Fig. 8a.

If $S_{0}$ is small, the first phase does not occur and innovation occurs at $t=0$, as depicted in Fig. 8b.

By using (11), we can calculate along the equilibrium path

$$
\frac{d p^{d}}{d S}=\frac{d p / d t}{d S / d t}=-\frac{\psi r p}{\mu D(p)},
$$

which can be compared to

$$
\frac{d p^{m}}{d S}=-\frac{r p}{D(p)}
$$

${ }^{22}$ For a monopolist, (see 14 above)

$$
\frac{\dot{p}^{m}}{p^{m}}=\frac{r}{1-v \frac{\varepsilon}{\varepsilon-1}} .
$$


Since as $p \rightarrow \bar{p} \varepsilon^{*} /\left(\varepsilon^{*}-1\right)$, the long-run monopoly price, $\mu \rightarrow 0$ while $\psi \rightarrow 1 /((2 \varepsilon-1) / \varepsilon)-v$

$$
\lim _{S \rightarrow 0}\left|\frac{d p^{m}}{d S}\right|<\lim _{S \rightarrow 0}\left|\frac{d p^{d}}{d S}\right| \rightarrow \infty .
$$

We can be more precise. In Appendix D we show that for the constant elasticity case,

$$
p^{d} \gtrless p^{m} \quad \text { as } \quad S \gtrless S^{* *} .
$$

The $p^{d}(S)$ and $p^{m}(S)$ functions are depicted in Fig. 9. Hence, for small $S$, $p^{d}<p^{m}$.

We can also be precise about the length of time the duopolists share the market, for the case of constant elasticity. Integrating (11), ${ }^{23}$ we obtain:

$$
p(t)=\frac{\bar{p} e^{r t}}{(1-1 / \varepsilon)(2-1 / \varepsilon)}+\frac{\bar{p}}{2-1 / \varepsilon} \quad(t \leqslant 0),
$$

where we measure $t$ from the date of exhaustion of the resource (i.e., $p(0)=\bar{p} /(1-1 / \varepsilon))$.

Solving for the value of $t, \hat{t}$, at which $p=\bar{p}$, we obtain

$$
\hat{t}=(2 / r) \ln (1-1 / \varepsilon) \text {. }
$$

Since $\dot{p} / p$ is lower with duopoly then with monopoly, and since for

${ }^{23}$ Equation (11) is a simple linear differential equation:

$$
\dot{p}=r p-k, \quad \text { where } \quad k=\frac{\bar{p} r}{2-1 / \varepsilon} .
$$

Hence

If at $t=0, p=\tilde{p} /(1-1 / \varepsilon)$, then

$$
\begin{aligned}
\ln (r p-k) & =r t+\hat{c}_{1}, \\
r p-k & =c_{1} e^{r t}, \\
r p & =c_{1} e^{r t}+k .
\end{aligned}
$$

$$
\frac{r \bar{p}}{1-1 / e}=c_{1}+k
$$

or

$$
\begin{aligned}
c_{1} & =r \bar{p}\left[\frac{1}{1-1 / \varepsilon}-\frac{1}{2-1 / \varepsilon}\right] \\
& =\frac{r \bar{p}}{(1-1 / \varepsilon)(2-1 / \varepsilon)} .
\end{aligned}
$$




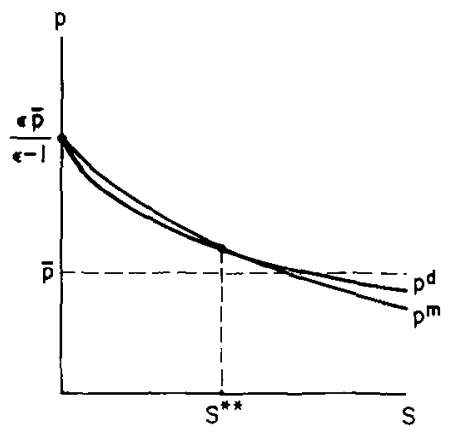

FIGURE 9

$S<S^{* *}, p^{d}(S)<p^{m}(S)$, it is immediate that for $S<S^{* *}$, the date of exhaustion is later than for monopoly. For $S>S^{* *}, p^{d}(S)>p^{m}(S)$, and $\mu \leqslant 1$, and hence the time taken to deplete the stock to $S^{* *}$ is greater for duopoly than for monopoly.

We summarize with

Proposition $5 b^{24}$ (i) If $S_{0}$ is small, $p_{t}^{s}<p_{t}^{d}<p_{t}^{m}$, all $t$.

(ii) If $\varepsilon^{\prime}=0$, there exists an $S^{* *}$, such that

$$
p^{d}(S) \gtrless p^{m}(S) \quad \text { as } \quad S \lessgtr S^{* *} .
$$

Moreover

$$
p^{d}\left(S^{* *}\right)>\bar{p}
$$

and

$$
p^{d}(S)>p^{s}(S) \quad \text { for all } S,
$$

the duopoly price exceeds the socially optimal price.

(iii) If $\varepsilon^{\prime}=0$,

$$
T_{2}^{d}>T^{m}>T^{s}>T_{1}^{d}
$$

The date of innovation is earlier and the date of exhaustion later than in either the socially optimal allocation or the monopoly.

(iv) If $M_{r}^{d}(S) \equiv p(1-(1-\mu) / \varepsilon)$, the marginal revenue of the resources owner when the stack is $S$ under the duopoly structure, then

\footnotetext{
${ }^{24}$ Assuming throughout that $v<(\varepsilon-1) / \varepsilon$.
} 
$M_{r}^{d}(S)>M^{m}(S)$ for all $S$ such that $p^{d}(S)>\max \left(p^{m}(S), \bar{p}\right)$. In addition, $M_{r}^{d}(S)>M^{m}(S)$ for all $S$ such that $p^{d}>2 \varepsilon \bar{p} / 2 \varepsilon-1 .^{25}$ For small $S$, the marginal revenue from an extra unit of the resource is higher under the duopoly market structure than under monopoly even though the price is lower. Thus, incentives for exploration will be greater in this environment; indeed, for all $p^{d}>\bar{p}(2 \varepsilon /(2 \varepsilon-1))$,

$$
M_{r}^{d}(S)>\bar{p},
$$

the marginal private return to additional resources exceeds the cost of production of the substitute, so there will be more exploration than is socially optimal.

It should be clear that what is essential for most of the analysis of this section is that there are only a "few" producers of the substitute and a "few" owners of the natural resource. The assumption of only two firms is not critical to the analysis.

\section{A Stackelberg Equilibrium for the Duopoly Problem}

In Section 7, we have explored a particular set of assumptions concerning the behavior of the two duopolists, that they behave in a Nash-Cournot way, taking the quantities sold by their competitors as given. This is not the only (or even necessarily the most persuasive) set of behavioral hypotheses. Elsewhere in this paper in discussing the behavior of a monopolist dealing with a large set of competitors we have employed an alternative assumption: that the monopolist knows the reaction of the competitors to any action which he undertakes; he finds the point along their "reaction function" at which his profits are maximized (see also Stiglitz [25]). When both the

${ }^{25}$ Using (10b)and (9a)

$$
M_{r}^{d}=\frac{2 \varepsilon-1}{\varepsilon} p-\bar{p}
$$

Hence

$$
M_{r}^{d}-M^{m}=\frac{2 \varepsilon-1}{\varepsilon} p^{d}(S)-\left(\frac{\varepsilon-1}{\varepsilon}\right) p^{m}(S)-\tilde{p} .
$$

For $p^{d}>2 \varepsilon \bar{p} / 2 \varepsilon-1$,

$$
M_{r}^{d}(S) \geqslant \bar{p}
$$

while for all $S$

$$
M^{m}=\frac{\varepsilon-1}{\varepsilon} p^{m} \leqslant \frac{\varepsilon-1}{\varepsilon} \frac{\varepsilon}{\varepsilon-1} \bar{p}=\bar{p}
$$


substitute and the resource are controlled by different monopolists, there is no natural "leader"- they would both appear to be equally powerful, and it for this reason that we have focused here on the Nash-Cournot equilibrium.

If the patent owner acts as the Stackelberg leader, and the resource owner is the follower, then it is obvious that (with a constant elasticity demand function), the equilibrium is identical to that described in Section 5 where the patent owner maximized his profit against a competitive resource owner.

Since the resource owner controlled the market prior to the invention, it seems, however, more natural to treat him as the Stackelberg leader. If the producer of the substitute takes the quantity supplied by the resource owner as given, his marginal revenue is (as before)

$$
p\left(1-\frac{(1-\mu)}{\varepsilon}\right)
$$

which he sets equal to his marginal cost, $\bar{p}$. Letting

$$
Q_{1}=\mu Q=\text { output of resource owner }
$$

we can rewrite the marginal revenue $=$ marginal cost equilibrium condition as

$$
Q_{1}=\frac{\varepsilon}{p}\left[\bar{p}-p\left(1-\frac{1}{\varepsilon}\right)\right] Q .
$$

Equation (13) can be viewed as the demand function facing the resource owner. Differentiating, we obtain

$$
\frac{d \ln Q_{1}}{d \ln p}=-(1+\varepsilon)-\frac{p(1-1 / \varepsilon)}{\bar{p}-p(1-1 / \varepsilon)}
$$

or

$$
\frac{Q_{1}}{p} \frac{d p}{d Q_{1}}=\frac{1}{-(1+\varepsilon)-\frac{p(1-1 / \varepsilon)}{\bar{p}-p(1-1 / \varepsilon)}}
$$

Hence, the marginal revenue of the resource owner is

$$
\begin{aligned}
p\left(1+\frac{Q_{1}}{p} \frac{d p}{\partial Q_{1}}\right) & =\frac{p\left(\varepsilon+\frac{p(1-1 / \varepsilon)}{\bar{p}-p(1-1 / \varepsilon)}\right)}{1+\varepsilon+\frac{p(1-1 / \varepsilon)}{\bar{p}-p(1-1 / \varepsilon)}} \\
& =p \frac{[\bar{p} \varepsilon+p(2-1 / \varepsilon-\varepsilon)]}{\bar{p}(1+\varepsilon)-p(\varepsilon-1)}
\end{aligned}
$$


This must increase at the rate of interest, so

$$
\dot{p}=r p /\left[1+\frac{p \bar{p}(1-1 / \varepsilon)}{(\bar{p} \varepsilon+p(2-1 / \varepsilon-\varepsilon))(\bar{p}(1+\varepsilon)-p(\varepsilon-1))}\right]<r p .
$$

As in the Stackelberg case analyzed earlier there is a kink in the demand schedule facing the resource owner. When $Q_{1}$ is sufficiently large that $p<\bar{p}$, marginal revenue is $p(1-1 / \varepsilon)$. But at $p$ slightly above $\bar{p}$, marginal revenue equals

$$
p\left(1-\frac{1}{2 \varepsilon}\right)
$$

which is larger. Thus, the equilibrium path consists of four phases (for $S$ sufficiently large) (see Fig. 10).

(a) for $0 \leqslant t \leqslant T_{1}, \dot{p} / p=r$, only resource owner produces;

(b) for $T_{1} \leqslant t \leqslant T_{2}, p=\bar{p}$, only resource owner produces;

(c) for $T_{2} \leqslant t \leqslant T_{3}, \dot{p} / p<r$, both produce;

(d) for $t \geqslant T_{3}, p=p^{m}$, only substitute is produced.

Price is continuous throughout. $T_{1}$ and $T_{2}$ are such that

$$
e^{-r\left(T_{2}-T_{1}\right)}=(1-1 / \varepsilon) /(1-1 / 2 \varepsilon) .
$$

The remainder of this analysis proceeds as before, e.g., for small $S$, $p^{d}<p^{m}$. The details of the analysis are left as an exercise to the reader.

The patent owner could, of course, take the price set by the resource owner as given; in that case, if $p$ exceeds $\bar{p}$, the substitute would be produced and drive out the resource. The resource owner recognizing this will solve exactly the same problem as we described in Section 6: he maximizes his revenue subject to the constraint that $p<\bar{p}$, and all the results reported there apply here as well.
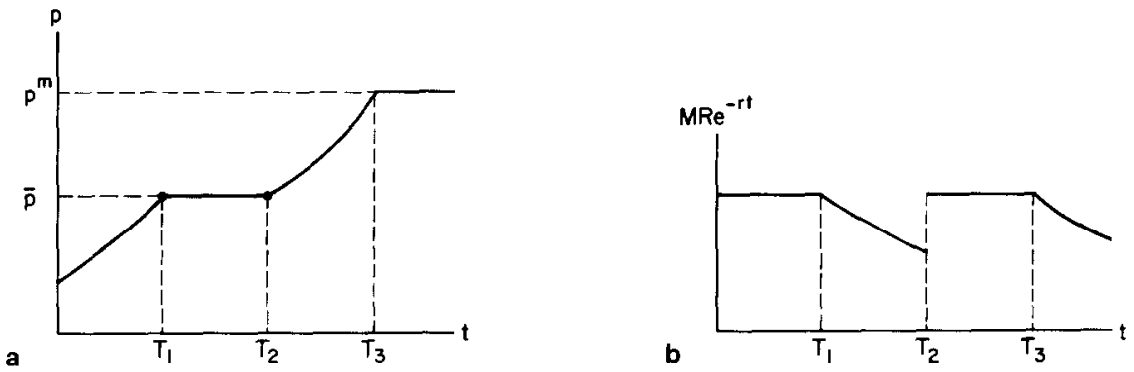

FIG. 10. (a) Price dynamics for Stackelberg duopoly. (b) Discontinuity in marginal revenue. 
Thus, as in so much of oligopoly, the precise character of this market equilibrium appears to be very sensitive to the behavioral assumptions postulated.

\section{CONCluding REMARKS}

In this paper we have attempted to extend the theory of monopolistic competition to an intertemporal setting. The theory in a general context is likely to be extremely complicated. No doubt that is why there have been so few attempts. We have cast the problems in the context of resource depletion in the presence of a new technology precisely because it offers strong qualitative results.

At issue was the manner in which "the market" would exploit an exhaustible resource with no extraction costs when there exists a substitute with an infinitely elastic supply. We have known, at least since the time of Cournot, that imperfectly competitive markets can support technologies of varying efficiency. Except for the polar cases of perfect competition and pure monopoly the best practice technique is generally not the only technique in use at an equilibrium. An intertemporal generalization of this was obtained for the duopoly models of Sections 7 and 8 and the Stackelberg equilibrium of Section 5. Interestingly enough, though, in each of the remaining cases that we analyzed, the market was found to be rational in the sense that resource exhaustion was found to precede innovation; the new technology takes over only when the natural resource is no longer available. This is, of course, not to say that the period of use of the natural resource is optimal in imperfect markets. It is possible to say a good deal about the biases that result, and they have been stated as Propositions $1 \mathrm{~b}-5 \mathrm{~b}$. It should be clear that our analysis is directly relevant to the question of the manner in which firms under perfect or imperfect competition physically depreciate their fixed capital by choosing the intensity with which to use their machinery.

The general presumption of excessive conservationism (Stiglitz [25]) on the part of monopoly is sustained, and extended to other imperfectly competitive environments. The widespread view that pure monopolies delay innovation is also supported. But considerable doubt is cast on the view that "limited competition" economies lie between the polar forms of perfect competition and perfect monopoly. In two models of limited competition, the market is even more conservationist than pure monopoly and innovation occurs earlier than in pure competition; while in one model exhaustion of the resource under limited competition occurs even later than in pure monopoly.

The results are summarized, for the case of constant elasticity demand functions, in Figs. 11a and $11 \mathrm{~b}$. 


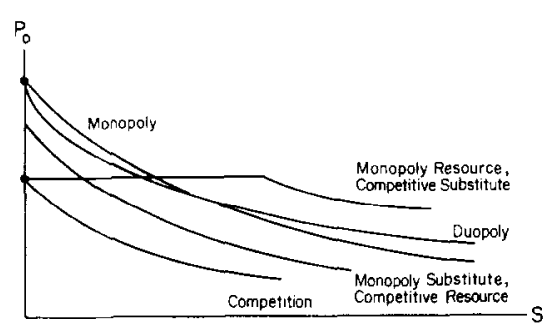

FIG. 11. (a) Price comparisons. (b) Comparison of dates of innovation.

These results have important further implications: we have already drawn attention to the likely biases in exploratory activity which will occur in the various market structures studied. Elsewhere, we explore the implications for the patterns of extraction prior to invention and for the incentives for invention itself. ${ }^{26}$

\section{APPENDIX A: Proof of Proposition 3a}

We wish to maximize

$$
\begin{aligned}
\operatorname{Max} \pi= & \int_{0}^{\tilde{T}_{2}} D(\tilde{p}(t)) \tilde{p}(t) e^{-r t} d t \\
& -\bar{p} \int_{\tilde{T}_{1}}^{\tilde{T}_{2}} e^{-r t} D(\tilde{p}(t)) d t-\tilde{p}_{0} S_{0}+e^{-r \tilde{T}_{2}} V,
\end{aligned}
$$

where $V$ is the present discounted value of steady state monopoly profits, subject to

$$
\begin{gathered}
\frac{d \ln \tilde{p}(t)}{d t} \leqslant r \\
\int_{0}^{\tilde{T}_{1}} D(\tilde{p}(t)) d t=S_{0} .
\end{gathered}
$$

${ }^{26}$ See Stiglitz and Dasgupta [27] and Stiglitz et al. [28]. 
There are two cases to consider:

(i) Elasticity constant or increasing with $Q$. Then the constraint (A.2) is binding, and we have

$$
\begin{gathered}
\tilde{p}(t)=\tilde{p}_{0} e^{r t} \quad \text { for } \quad 0 \leqslant t \leqslant \tilde{T}_{1}, \\
p\left(\tilde{T}_{2}\right)=\tilde{p}_{0} e^{r \tilde{T}_{2}}=\frac{\bar{p} \varepsilon^{*}}{\varepsilon^{*}-1} .
\end{gathered}
$$

Hence differentiating (A.3) with respect to $\tilde{p}_{0}$, we obtain

$$
\tilde{p}_{0} \frac{d \tilde{T}_{1}}{d \tilde{p}_{0}}=-\int_{0}^{\tilde{T}_{1}} D^{\prime} \tilde{p} d t / D\left(\tilde{p}\left(\tilde{T}_{1}\right)\right)=\frac{\int_{0}^{\tilde{T}_{1}} \varepsilon D(\tilde{p}) d t}{D\left(\tilde{p}\left(\tilde{T}_{1}\right)\right)} .
$$

Thus

$$
\begin{aligned}
\frac{\partial \pi}{d \tilde{p}_{0}} & =\int_{0}^{\tilde{T}_{2}}\left(D^{\prime} \tilde{p}+D\right) d t+e^{-r \tilde{T}_{1}} \frac{\bar{p}}{\tilde{p}_{0}} D\left(\tilde{p}\left(\tilde{T}_{1}\right)\right) \frac{\int_{0}^{\tilde{T}_{1}} \varepsilon D(\tilde{p}) d t}{D\left(\tilde{p}\left(\tilde{T}_{1}\right)\right)}-S_{0}-\bar{p} \int_{\tilde{T}_{1}}^{\tilde{T}_{2}} D^{\prime} d t \\
& =\int_{0}^{\tilde{T}_{1}} D\left[1-\varepsilon\left(1-\frac{\bar{p}}{\tilde{p}_{0} e^{r \tilde{T}_{1}}}\right)\right] d t-S_{0}+\int_{\tilde{T}_{1}}^{\tilde{T}_{2}} D\left(1-\varepsilon\left(1-\frac{\bar{p}}{\tilde{p}}\right)\right) d t \\
& =-\int_{0}^{\tilde{T}_{1}} \varepsilon\left(1-\frac{\bar{p}}{\tilde{p}_{0} e^{r \tilde{T}_{1}}}\right) d t+\int_{\tilde{T}_{1}}^{\tilde{T}_{2}} D\left(1-\varepsilon\left(1-\frac{\bar{p}}{\tilde{p}}\right)\right) d t .
\end{aligned}
$$

At $\tilde{T}_{1}=\tilde{T}_{2}, \tilde{p}_{0} e^{r \tilde{T}_{1}}>\bar{p}$, and $\partial \pi / \partial p_{0}<0$.

At $\tilde{p}_{0}=p_{0}^{s}$, the socially optimal price, $\tilde{p}_{0} e^{r \tilde{T}_{1}}=\bar{p}$.

Since $\tilde{p}<p_{T^{m}}^{m}=\bar{p} /(1-1 / \varepsilon)$,

$$
\int D\left(1-\varepsilon\left(1-\frac{\bar{p}}{\tilde{p}}\right)\right) d t>\int D[1-\varepsilon(1-(1-1 / \varepsilon))] d t=0
$$

Hence

$$
\frac{\partial \pi}{\partial \tilde{p}_{0}}>0
$$

Hence $\tilde{p}_{0}>p_{0}^{s}$ but $\tilde{p}_{0}<p_{0}^{m}$.

(ii) Elasticity decreasing with $Q$. This is the case for which a monopolist would increase his price at a rate less than the rate of interest. We have to show that it is never profitable for the patent owner to buy the resource from the competitors and thus increase his price at a rate less than 
the rate of interest. Assume it were, and let the price path $\tilde{p}(t)$ be the optimal price trajectory where

$$
\tilde{p}(t) \leqslant p_{0} e^{r t}
$$

Clearly,

$$
\int_{0}^{\tilde{T}_{1}} \tilde{p}(t) e^{-r t} Q d t \leqslant \int_{0}^{\tilde{T}_{1}} p_{0} Q d t=p_{0} S_{0}
$$

Consider the new price path, $\hat{p}(t)$,

$$
\hat{p}\left(\hat{T}_{1}+\tau\right)=\tilde{p}\left(\tilde{T}_{1}+\tau\right) \quad \text { for all } \tau \geqslant 0,
$$

but

$$
\hat{p}(t)=\hat{p}\left(\hat{T}_{1}\right) e^{-r\left(\hat{T}_{1}-t\right)}<\tilde{p}(t) \quad \text { for all } 0 \leqslant t \leqslant \hat{T}_{1}
$$

Clearly

$$
\int_{0}^{\hat{T}_{1}} \hat{p}(t) Q e^{-r t} d t=\hat{p}(0) S_{0}
$$

Since $\hat{T}_{1}<\tilde{T}_{1}$, the patent owner could have paid $\hat{p}_{0}>p_{0}$ for the resource, and his profits would have been greater than along the price path $\tilde{p}$ :

$$
\begin{aligned}
\int_{0}^{\infty} \hat{p} Q e^{-r t} d t-\hat{p}_{0} S_{0}-\int_{T_{1}}^{\infty} \bar{p} Q e^{-r t} d t & =e^{-r \hat{T}_{1}} \int_{0}^{\infty}\left(\tilde{p}\left(\hat{T}_{1}+\tau\right)-\bar{p}\right) Q e^{-r \tau} d \\
& >e^{-r \tilde{T}_{1}} \int_{0}^{\infty}\left(\tilde{p}\left(\hat{T}_{1}+\tau\right)-\bar{p}\right) Q e^{-r \tau} d t
\end{aligned}
$$

Thus $\tilde{p}$ could not have been optimal.

\section{APPENDIX B: Proof of Proposition 4a}

We wish to

$$
\underset{\left\{p(t), T_{1}, T_{2}\right]}{\operatorname{maximize}} \pi \equiv \int_{0}^{T_{1}} D(p(t)) p(t) e^{-r t} d t+\int_{T_{1}}^{T_{2}} \bar{p} D(\bar{p}) e^{-r t} d t \quad \text { s.t. }
$$




$$
\begin{gathered}
p(t) \leqslant \bar{p}, \\
\int_{0}^{T_{1}} D(p(t)) d t+\int_{T_{1}}^{T_{2}} D(\bar{p}) d t=S_{0} .
\end{gathered}
$$

There are two cases to consider: (i) The elasticity of demand is constant, ${ }^{27}$ and (ii) the elasticity of demand varies with $Q$.

In the former case,

$$
p(t)=p_{0} e^{r t}
$$

Then we have a single control variable, $p_{0}$, with which we are concerned: since (with elasticity greater than unity, constraint (B.2) will also be binding at $T_{1}$ )

$$
\begin{gathered}
p\left(T_{1}\right)=p_{0} e^{r T_{1}}=\bar{p}, \\
-p_{0} \frac{d T_{1}}{d p_{0}}=-\frac{1}{r},
\end{gathered}
$$

and, from (B.3)

$$
p_{0} \frac{d T_{2}}{d p_{0}}=-\int_{0}^{T_{1}} D^{\prime} p d t / D(\bar{p})
$$

Hence

$$
\begin{aligned}
\frac{d \pi}{d p_{0}} & =\int_{0}^{T_{1}}\left(D^{\prime} p+D\right) d t+\bar{p} D(\bar{p}) e^{-r T_{2}} \frac{d T_{2}}{d p_{0}} \\
& =\int_{0}^{T_{1}} D(1-\varepsilon) d t+\frac{\bar{p}}{p_{0} e^{r T_{2}}} \int_{0}^{T_{1}} \varepsilon D(p) d t .
\end{aligned}
$$

If $T_{1}=T_{2}, p_{0} e^{r T_{2}}=\bar{p}$, and

$$
\frac{d \pi}{d p_{0}}=\int_{0}^{T_{1}} D d t>0
$$

Hence $T_{2}>T_{1}$.

At $T_{1}=0, d \pi / d p_{0}=0$.

${ }^{27}$ Or it increases with $Q$, but there is speculation so $d \ln p / d t$ is restricted to be less than or equal to $r$ :

$$
\frac{d \ln p}{d t} \leqslant r
$$


Differentiating $\pi$ again, we have, at $T_{1}=0$,

$$
p_{0} \frac{d^{2} \pi}{d p_{0}^{2}}=-\left[D(1-\varepsilon)+\frac{\bar{p} \varepsilon}{p_{0} e^{r T_{2}}} D\right] / r>0,
$$

if $e^{r T_{2}}>\varepsilon /(\varepsilon-1)$. Hence, if $S_{0}$ is small, $p_{0}=\bar{p}$; if $S_{0}$ is large, $p_{0}<\bar{p}$.

The case with $\varepsilon$ not constant is somewhat more subtle. To establish this result we use a perturbation argument. It is easy to show that during $\left(0, T_{1}\right)$

$$
\frac{d R^{\prime}}{d t}=r R^{\prime}
$$

where $R^{\prime}=$ marginal revenue.

Clearly, the cartel is indifferent between selling an extra unit at any date between 0 and $T_{1}$. In the profit-maximizing equilibrium, it must be indifferent between selling a unit just before $T_{1}$, reducing the present discounted value of revenue by

$$
R^{\prime}(Q) e^{-r T_{1}}
$$

and selling a unit more just beyond $T_{2}$, which raises the (present discounted value of) revenue by

$$
\bar{p} e^{-r T_{2}}
$$

Hence

$$
R^{\prime}(Q) e^{-r T_{1}}=\bar{p} e^{-r T_{2}}
$$

or

$$
e^{-r\left(T_{2}-T_{1}\right)}=1-\frac{1}{\varepsilon},
$$

establishing that $T_{2}>T_{1}$. If $D(\bar{Q}) \equiv \bar{p}$, and

$$
S_{0}<-\frac{\bar{Q}}{r} \ln \left(1-\frac{1}{\varepsilon}\right)
$$

then

$$
p_{0}=\bar{p} \quad\left(Q_{0}=\bar{Q}\right) .
$$




\section{APPENDIX C: Derivation of Duopoly DifFerential Equation}

Rewrite (10b) as

$$
p(2-1 / \varepsilon-(1-\mu / \varepsilon))=\bar{p} .
$$

From $(9 a)$ we thus obtain

$$
M R=p(2-1 / \varepsilon)-\bar{p}
$$

so

$$
\frac{\dot{p}(2-1 / \varepsilon)+p \varepsilon^{\prime} \dot{Q} / \varepsilon^{2}}{p(2-1 / \varepsilon)-\bar{p}}=r
$$

or since

$$
\frac{\varepsilon^{\prime} Q}{\varepsilon^{2}} \frac{\dot{Q}}{Q}=-v \frac{\dot{p}}{p}
$$

we have

$$
\frac{\dot{p}[2-1 / \varepsilon-v]}{p(2-1 / \varepsilon)-\bar{p}}=r
$$

APPENDIX D: Proof THAT $p^{d} \lessgtr p^{m}$

AS $S \lessgtr S^{* *}$ IF $\varepsilon^{\prime}=0$ (Constant Elasticity of Demand)

Solve (12) for $p^{d}=p^{d}(S)$ and $\left(12^{\prime}\right)$ for $p^{m}=p^{m}(S)$. Since both functions are monotonic, they can be inverted. Define

$$
\begin{aligned}
S_{1} & =\left(p^{d}\right)^{-1}(p), \\
S_{2} & =\left(p^{m}\right)^{-1}(p), \\
\Delta & =S_{1}-S_{2} .
\end{aligned}
$$

Then using (10b) and $(11)^{28}$

${ }^{28}$ From (10b), $\mu=\varepsilon \bar{p} / p-(\varepsilon-1)$. From $(11), \psi=1-\bar{p} / p(2-a)$. 


$$
\begin{aligned}
\frac{d \Delta}{d p} & =-\frac{D}{r p}\left[\frac{\mu}{\psi}-1\right] \\
& \left.=-\frac{D}{r p} \frac{[\bar{p} x-(1-a)] / a}{1-\bar{p} x /(2-a)}-1\right] \\
& =-\frac{D}{r p} \frac{\left[\bar{p} x\left(\frac{1}{a}+\frac{1}{2-a}\right)-\frac{1}{a}\right]}{1-\bar{p} x / 2-a} \\
& =-\frac{D}{\operatorname{arp}}\left[\frac{2 \bar{p} x-(2-a)}{2-\bar{a}-\bar{p} x}\right],
\end{aligned}
$$

where $x=1 / p, a=1 / \varepsilon$. Hence, if $\bar{x}=1 / \bar{p}$

$$
\frac{d \Delta}{d x}=\left[\frac{x-(1-a / 2) \bar{x}}{(2-a) \bar{x}-x}\right] \frac{2 x^{\epsilon+1} k}{a r} .
$$

At $p=\bar{p}, x=\bar{x}$, and $x-(1-a / 2) \bar{x}=a \bar{x} / 2$.

At $p=p^{m}=\bar{p} /(1-a), x=(1-a) \bar{x}$, and

$$
x-(1-a / 2) \bar{x}=-a \bar{x} / 2 .
$$

Hence, since $\Delta=0$ at $x=(1-a) \bar{x}$, letting $z \equiv 2(1-a / 2)^{\epsilon} \bar{x}^{\epsilon} k / a r$,

$$
\begin{aligned}
\Delta\left(\frac{1}{\bar{p}}\right) & \left.=\int_{(1-a) \bar{x}}^{\bar{x}} \frac{d \Delta}{d x} d x>\int_{(1-a) \bar{x}}^{\bar{x}}\left(x-\left(1-\frac{a}{2}\right) \bar{x}\right) d x\right) z \\
& =\left(\frac{x^{2}}{2}-\left.x\left(1-\frac{a}{2}\right) \bar{x}\right|_{(1-a) \bar{x}} ^{\bar{x}}=0\right.
\end{aligned}
$$

since

$$
\frac{d\left(\frac{x^{\varepsilon+1}}{(2-a) \bar{x}-x}\right)}{d x}>0 .
$$

It is also immediate that since

$$
\frac{d \Delta}{d x} \gtrless 0 \quad \text { as } \quad x \gtrless(1-a / 2) / \bar{p},
$$

there exists a unique $x^{*},(1-a) \bar{x}<x^{*}<\bar{x}$, such that

$$
\Delta\left(x^{*}\right)=0 .
$$


Moreover $x^{*}>(1-a / 2) \bar{x}$. This implies that there exists a unique value of $S$ for which $p^{d}=p^{m}$, and that the two are equal at a value of $p>\bar{p}$. Hence, since for $p<\bar{p}$ the price differential equations are the same, there exists a unique $S^{* *}$ such that $p^{d}(S) \gtrless p^{m}(S)$ as $S \lessgtr S^{* *}$.

\section{REFERENCES}

1. A. Cournot, "Researches into the Mathematical Principles of the Theory of Wealth." 1838 .

2. J. Cremer and M. Weitzman, OPEC and the monopoly price of world oil, European Econ. Rev. 8 (1976), 155-164.

3. P. Dasgupta, R. Gilbert, and J. E. Stiglitz, Market structures, research and development and exhaustible resources, London School of Economics, mimeo, 1977.

4. P. Dasgupta and G. Heal, The optimal depletion of exhaustible resources, Rev. Econ. Studies 41, Symposium on the Economics of Exhaustible Resources (1974), 3-28.

5. P. Dasgupta and G. M. Heal, Economic theory and exhaustible resources, Cambridge Economic Handbooks, James Nisbet, Welwyn Garden City, England, 1979.

6. P. Dasgupta AND J. E. Stiglitz, "Uncertainty and Rates of Extraction under Alternative Institutional Arrangements," IMSSS Technical Report No. 179, Stanford University, 1976.

7. P. Dasgupta and J. E. STiglitz, "Market Structure and the Nature of Innovative Activity," invited paper presented at the World Congress of the International Economics Association on Economic Growth and Resources, Tokyo, August 27-September 3, 1977.

8. P. Dasgupta AND J. E. Stiglitz, Industrial structure and the nature of innovative activity, Econ. J. 90 (1980), 266-293.

9. P. Dasgupta AND J. E. Stiglitz. Uncertainty, market structure, and the speed of R \& D, Bell J. Econ. 11 (1980), 1-28.

10. P. Dasgupta and J. E. Stiglitz, Resource depletion under technological uncertainty, Econometrica 49 (1981), pp. 85-104.

11. A. Dixit and J. E. Stiglitz, Monopolistic competition and optimum product diversity, Amer. Econ. Rev. 67 (1977), 297-308.

12. R. GiLbert, Dominant firm pricing policy in a market for an exhaustible resource, Bell $J$. Econ. 9 (1978). 385-395.

13. E. Hnyilicza And R. Pindyck. Pricing policies for a two-part exhaustible resource cartel: The case of OPEC, European Econ. Rev. 8 (1976), 139-154.

14. M. HoEl. Resource extraction under some alternative market structures, Meisenheim Am Glan: Verlag Anton Hain (1978).

15. H. Hotelling, The economics of exhaustible resources, J. Pol. Econ. 39 (1931), $137-175$.

16. J. NeF, An early energy crisis and its consequences, Sci. Amer. (November 1977).

17. S. SALANT, Exhaustible resources and industrial structure: A Nash-Cournot approach to the world oil market, J. Pol. Econ. 84 (1976), 1079-1093.

18. S. SALOP, "Monopolostic Competition Reconstituted-or-Circular Fashions in Economic Thought," Federal Reserve Board, Special Studies Paper No. 89, Washington, (1977).

19. R. M. Solow, The economics of resources or the resources of economics, Amer. Econ. Rev. 64, Papers and Proceedings (1974), 1-14.

20. A. M. SPEnCE, Product selection, fixed costs and monopolistic competition, Rev. Econ. Studies 43 (1976), 217-235. 
21. E. Steinmuller, On the economics of timber famine in 16th century england, Stanford University, mimeo, 1976.

22. J. E. Stiglitz, The efficiency of Market Prices in Long Run Allocations in the Oil Industry, in "Studies in Energy Policy" (G. Brannon, Ed.), pp. 55-99, Ballinger, Cambridge, Mass., 1975 (abbreviated version of report written for the Ford Energy Policy Project, August).

23. J. E. STIGLITz, Growth with exhaustible natural resources: Efficient and optimal growth paths, Rev. Econ. Studies 41, Symposium on the Economics of Exhaustible Resources (1974a), 123-138.

24. J. E. STIGLITZ, Growth with exhaustible natural resources, and the competitive economy, Rev. Econ. Studies 41, Symposium on the Economics of Exhaustible Resources (1974b), $139-152$.

25. J. E. Stiglitz, Monopoly and the rate of extraction of exhaustible resources, Amer. Econ. Rev. 66 (1976), 655-661.

26. J. E. STIGLITZ, Information and competition, Oxford Econ. Papers, in press.

27. J. E. STiglitz AND P. DASGupta, Market structure and resource extraction under undertainty, Scandinavian Journal of Economics, 83 (1981), 318-333.

28. J. E. Stiglitz, R. Gilbert, and P. Dasgupta, Invention and innovation under alternative market structures: The case of natural resources, Econometric Research Program Research Memorandum No. 263 Princeton University, March, 1980.

29. J. L. SWEENEY, Economics of depletable resources: Market forces and intertemporal bias, Eev. Econ. Studies 44 (1977), 125-142. 